\title{
RENAL NUTRITION
}

\section{Comparison between direct and indirect methods to diagnose malnutrition and cardiometabolic risk in haemodialisys patients}

\author{
K. P. Balbino, ${ }^{1}$ A. P. S. Epifânio, ${ }^{1}$ S. M. R. Ribeiro, ${ }^{1}$ L. D. M. da Silva, ${ }^{2}$ M. G. Gouvea ${ }^{2}$ \& \\ H. H. M. Hermsdorff ${ }^{1}$
}

${ }^{1}$ Department of Nutrition and Health, Universidade Federal de Viçosa, Viçosa, Minas Gerais, Brazil

${ }^{2}$ Division of Nephrology, São João Batista Hospital, Viçosa, Brazil

\author{
Keywords \\ cardiometabolic risk, chronic kidney disease, \\ malnutrition, modified global subjective \\ assessment, objective global assessment, ROC \\ curve.

\section{Correspondence \\ H. H. M. Hersmdorff, Department of Nutrition and Health, Universidade Federal de Viçosa, Avenue PH Rolfs s/n, Viçosa, Minas Gerais 36570-900, Brazil. \\ Tel.: +55 3138991269 \\ Fax.: +553138992541 \\ E-mail: helenhermana@ufv.br}

\section{How to cite this article} \\ Balbino K.P., Epifânio A.P.S., Ribeiro S.M.R., da \\ Silva L.D.M., Gouvea M.G., Hermsdorff H.H.M. \\ (2017) Comparison between direct and indirect \\ methods to diagnose malnutrition and \\ cardiometabolic risk in haemodialisys patients. \\ J Hum Nutr Diet. 30, 646-654 \\ doi: $10.1111 / \mathrm{jhn} .12468$
}

\begin{abstract}
Background: The present study aimed to evaluate the nutritional status of patients undergoing haemodialysis (HD) by comparing nutritional risk scores with biochemical, anthropometric and body composition variables.

Methods: Eighty-five individuals [65.9\% male, mean (SD) age 62 (14) years] participated in a cross-sectional study. Global Objective Assessment (GOA) and Modified Global Subjective Assessment (mGSA) scores, as well as biochemical, anthropometric and body composition data, were collected using standardised procedures.

Results: The prevalence of malnutrition ranged from 20.0\% (\% body fat by electrical bioimpedance) to $95.3 \%$ (by GOA), depending on the indicator or score used. According to the waist circumference, $61.2 \%$ of the individuals presented abdominal obesity and visceral adipose tissue was excessive in $20 \%$ of them. Malnutrition diagnosis by GOA showed the relationship between the anthropometric and body composition indicators, as assessed by the extent that the ratings of risk nutritional/mild malnutrition and mainly moderate malnutrition were accompanied by a significant decrease in nutritional status and body composition variables. However, with respect to categories of mGSA, no statistically significant differences were observed for nutritional status and body composition variables. In the receiver operator characteristic curve analyses, mGSA and GOA were good indicators for diagnosing malnutrition because both achieved an AUC $>0.5$.

Conclusions: mGSA and GOA were more sensitive with respect to identifying individuals at nutritional risk compared to the isolated anthropometric indicators, thus indicating their utility in diagnostic malnutrition. However, individuals at high nutritional risk also presented cardiometabolic risk, as diagnosed mainly by central fat indicators, suggesting the application of both malnutrition and cardiometabolic risk markers in HD patients.
\end{abstract}

\section{Introduction}

Protein-energy malnutrition (PEM) is highly prevalent in individuals undergoing haemodialysis $(\mathrm{HD})^{(1,2)}$ because of a reduced protein and energy intake, inflammation, resistance to anabolic hormones such as insulin and growth hormone, and the loss of amino acids and other nutrients in the dialysate and catabolism of muscle protein $^{(1,3,4)}$.

PEM is associated with increased morbidity and mortality ${ }^{(5)}$ and a worse quality of life in this population ${ }^{(6,7)}$ and so several indicators have been evaluated aiming to assess the nutritional status of individuals undergoing $\mathrm{HD}$, such as the Subjective Global Assessment (SGA) ${ }^{(8)}$, 
the malnutrition-inflammation score ${ }^{(9)}$, anthropometric and biochemical indicators and bioelectrical impedance analysis (BIA) ${ }^{(10)}$. However, no indicator is considered as the gold standard ${ }^{(11)}$ and therefore the combined use of markers for assessing nutritional-inflammatory status in HD individuals is suggested ${ }^{(12)}$.

Thus, Kalantar-Zadeh et al. (13) developed Modified Global Subjective Assessment (mGSA) as an alternative to the classic anthropometric nutritional assessment for chronic kidney disease. The mGSA is based on a clinical assessment derived from rating scales calculated from a brief history and physical examination ${ }^{(14)}$, which assists in predicting clinical outcomes associated with nutrition under different conditions ${ }^{(15,16)}$. The mGSA assimilates the advantages of SGA and is a reproducible and validated method for assessing the nutritional status of individuals undergoing $\mathrm{HD}$, in a practical manner and at low cost ${ }^{(17,18)}$.

The Global Objective Assessment (GOA) is underutilised in individuals undergoing $\mathrm{HD}$, even though it is a rating numerical system that can identify malnutrition by combining objective indicators of nutritional assessment. Therefore, this could be more specific than mGSA (19), although only one study has evaluated the relationship of mGSA and GOA with direct objective measures ${ }^{(20)}$.

The present study aimed to evaluate the nutritional status of HD patients, comparing nutritional risk scores with biochemical, anthropometric and body composition variables.

\section{Materials and methods}

\section{Study sample}

This cross-sectional study included 85 individuals (aged 20-86 years) undergoing $\mathrm{HD}$, from a single dialysis centre. Non-inclusion criteria were individuals who expressed no interest in participating in the present study, or individuals who had been undergoing HD treatment for less than 1 month, as well as those with hearing impairment, newly implanted catheters, haemodynamic instability, as assessed by the medical sector, or those who were unable to remain standing for anthropometric evaluation. The study was approved by the Ethics Committee in Human Research of the Universidade Federal de Viçosa (Reference number 27364314.8.0000.5153) and was conducted in accordance with the guidelines of the Declaration of Helsinki. Written informed consent was obtained from all patients.

\section{Nutritional status and diagnosis}

The clinical and nutritional status were assessed by mGSA, GOA, albumin, anthropometry and body composition assessment. The mGSA used was the adapted model proposed by Kalantar-Zadeh et al. ${ }^{(13)}$ for kidney dialysis patients. We also completed a GOA score, as proposed by Martins (19), for kidney dialysis patients. Serum albumin was determined according to standard Labtest procedures (Vista Alegre, Lagoa Santa, Brazil).

Anthropometry was performed approximately $30 \mathrm{~min}$ after the end of the HD session, including dry weight $(\mathrm{kg})$, height $(\mathrm{cm})$, waist (WC), hip and arm (AC) circumferences, and skinfold thickness (ST) (triceps, biceps, subscapular and suprailiac) in accordance with standard procedures ${ }^{(21-23)}$.

The determination of ST was taken using a caliper (Model MGF 771, Cescorf, Porto Alegre, Brazil) and the measurements were performed in triplicate ${ }^{(24)}$. AC was measured at the midpoint between the acromion process of the scapula and the olecranon. At the time of measurement, the upper limbs were positioned parallel to the individual trunk. The measure was compared with the reference values of US Hanes ${ }^{(25)}$. The tricep ST and AC measurements were used to calculate the arm muscle circumference ${ }^{(26)}$, adjusted-arm muscle area ${ }^{(27)}$ and arm fat area ${ }^{(25)}$.

WC was obtained at the largest circumference, and the measurement was carried out during the time of expiration and analysed in accordance with the cut-off points of the World Health Organization (WHO) ${ }^{(28)}$, considering the risk of diseases associated with obesity, and also in accordance with the International Diabetes Federation (IDF) ${ }^{(29)}$.

Hip circumference was measured at the gluteal region corresponding to the most protuberant hips and buttocks without tissue compression ${ }^{(23)}$. From the division of WC by hip circumference, the waist-hip ratio (WHR) was calculated, with the adoption of the cut-off points recommended by the WHO ${ }^{(28)}$ for risk of cardiovascular disease.

Body composition was also evaluated approximately $30 \mathrm{~min}$ after the end of HD session by BIA (model BC150; Tanita, Tokyo, Japan). The physical constitution scale and visceral adipose tissue (VAT) were also determined by BIA. In accordance with the manufacturer's information, the VAT accumulation risk is calculated by estimating the VAT area via the BIA method on the basis of magnetic resonance imaging. The physical constitution scale assesses muscle and body fat levels and, from these results, one of nine body types is selected.

The sum of triceps, biceps, subscapular and suprailiac ST (sum of four skinfolds thickness; $\Sigma 4$ ST) according to the formula of Durnin and Womersley ${ }^{(30)}$ for determining body fat percentage was derived using the equation of Siri ${ }^{(31)}$.

Subjects were classified according to the presence, or not, of malnutrition by different indicators, regardless 
of intensity of nutritional impairment. The criteria adopted for the diagnosis of malnutrition were:

- mGSA: Nutritional risk/mild malnutrition (9-23 points), moderate malnutrition (24-31 points), severe malnutrition (32-39 points) or very serious malnutrition ( $\geq 40$ points) ${ }^{(13)}$;

- GOA: Nutritional risk/mild malnutrition $(\geq 7$ points), moderate malnutrition (13-18 points) or severe malnutrition ( $\geq 19$ points) ${ }^{(19)}$;

- Body mass index (BMI): $<18.5 \mathrm{~kg} \mathrm{~m}^{-2}$ for adults, in accordance with the cut-off points established by the World Health Organization ${ }^{(32)}$ and BMI $<22 \mathrm{~kg} \mathrm{~m}^{-2}$ for the elderly, in accordance with the cut-off points established by Lipschitz ${ }^{(33)}$;

- AC, Arm muscle circumference and Triceps ST: $<90 \%$ of adequacy, taking the 50th percentile as reference, according to age and sex for the population ${ }^{(25,34)}$. The categories for the diagnosis were: severe malnutrition $<70 \%$, moderate malnutrition $70-80 \%$ and mild malnutrition $80-90 \%$, according to Blackburn and Thornton (35).

- Adjusted-arm muscle area: <15th percentile. The 15 th percentile was used as reference according to age and sex (34), including the categories: severe malnutrition $<5$ th percentile and mild/moderate malnutrition $>5$ th and $<15$ th percentile, according to Frisancho (25).

- Arm fat area: <25 percentile according Rombeau et al. ${ }^{(36)}$, considering the 25 th percentile for age and sex, proposed by Frisancho (34).

- Body fat: Body fat percentage (BF\%) by BIA, according to sex and sex. Females: $18-39$ years $<21 \%$; 40-59 years $<23 \%$ and $60-99$ years $<24 \%$; Males: $18-39$ years $<8 \%$; $40-59$ years $<11 \%$ and $60-99$ years $<13 \%{ }^{(37,38)}$.

- Albumin: $<4.0 \mathrm{~g} \mathrm{dL}^{-1(39)}$.

- Normalised protein equivalent of nitrogen appearance (nPNA) was calculated from the Kt/V urea and serum urea ${ }^{(39)}$. A value of nPNA was considered as normal when $\geq 1.0^{(40)}$.

With respect to being overweight and cardiometabolic risk, the criteria considered were :

- $\quad$ BMI: $>25.0 \mathrm{~kg} \mathrm{~m}^{-2}$ for adults, in accordance with the cut-off points established by the World Health Organization (32) and $\mathrm{BMI}>27 \mathrm{~kg} \mathrm{~m}^{-2}$ for the elderly, in accordance with the cut-off points established by Lipschitz ${ }^{(33)}$;

- WC: high risk for metabolic complications: $\geq 80 \mathrm{~cm}$ for women and $\geq 94$ for men and very high risk: $\geq 88 \mathrm{~cm}$ for women and $\geq 102$ for men, in accordance with the cut-off points established by the $\mathrm{WHO}^{(28)}$ and $\geq 80 \mathrm{~cm}$ for women and $\geq 90 \mathrm{~cm}$ for men, in accordance with the IDF ${ }^{(29)}$.
- WHC: $>0.85$ for women and $>1.0$ for men, in accordance with the WHO ${ }^{(28)}$.

- Body fat: BF\% by BIA, according to sex and age. Females: $18-39$ years $>33 \%$; 40-59 years $>34 \%$ and $60-$ 99 years $>36 \%$; Males: $18-39$ years $>20 \%$; 40-59 years $>22 \%$; and $60-99$ years $>25 \%$. BF\% by $\Sigma 4$ ST, according to sex and age. Females: $18-34$ years $>35 \%$; 35-55 years $<38 \%$; and $>55$ years $>35 \%$; Males: $18-34$ years $>22 \%$; $35-55$ years $>25 \%$; and $>55$ years $>23 \%{ }^{(37,38)}$.

- $\quad$ VAT: Excessive levels: scale 13-59.

- Physical constitution scale: Body types 1,2 and 3.

\section{Statistical analysis}

Statistical analysis was performed using SPSS, version 20.0 (SPSS, Inc., Chicago, IL). Data are expressed as frequencies, mean (SD) or median and interquartile ranges, depending on the variable's distribution, and as confirmed by the Shapiro-Wilk test.

To compare the variables of nutritional status and body composition according to the categories of mGSA and GOA, analysis of variance was performed complemented by Hochberg's GT2 test or Games-Howell; or the Kruskal-Wallis test complemented by Bonferroni correction in accordance with the variable's distribution. The difference between the frequency of malnutrition according to sex and age, for the different indicators of evaluation, was observed using Pearson's chi-squared test or Fisher's exact test. An analysis of the receiver operator characteristic (ROC) curve was made using $\mathrm{Kt} / \mathrm{V}$ urea as HD success. $P<0.05$ was considered statistically significant.

\section{Results}

The prevalence of malnutrition ranged from $20.0 \%$ to 95.3\% when diagnosed, respectively, by the BIA and GOA (Fig. 1). mGSA and GOA diagnosed the hightest percentages of malnutrition (89.4\% and $95.3 \%$, respectively). Arm fat area and triceps ST comprised the indicators that identified a higher prevalence of malnutrition $(78.3 \%$ and $82.1 \%$, respectively).

Malnutrition occurrence using AC, arm muscle circumference, adjusted-arm muscle area, arm fat area and nPNA was significantly higher among men compared to women (Fig. 1). When comparing the frequency of malnutrition by age, a higher prevalence of malnutrition among the elderly was indicated by BMI classification and nPNA (Fig. 1).

When we evaluated being overweight and cardiometabolic risk in the sample, we found that $20.0 \%$ were overweight by BMI. Some $22.4 \%$ of the individuals 


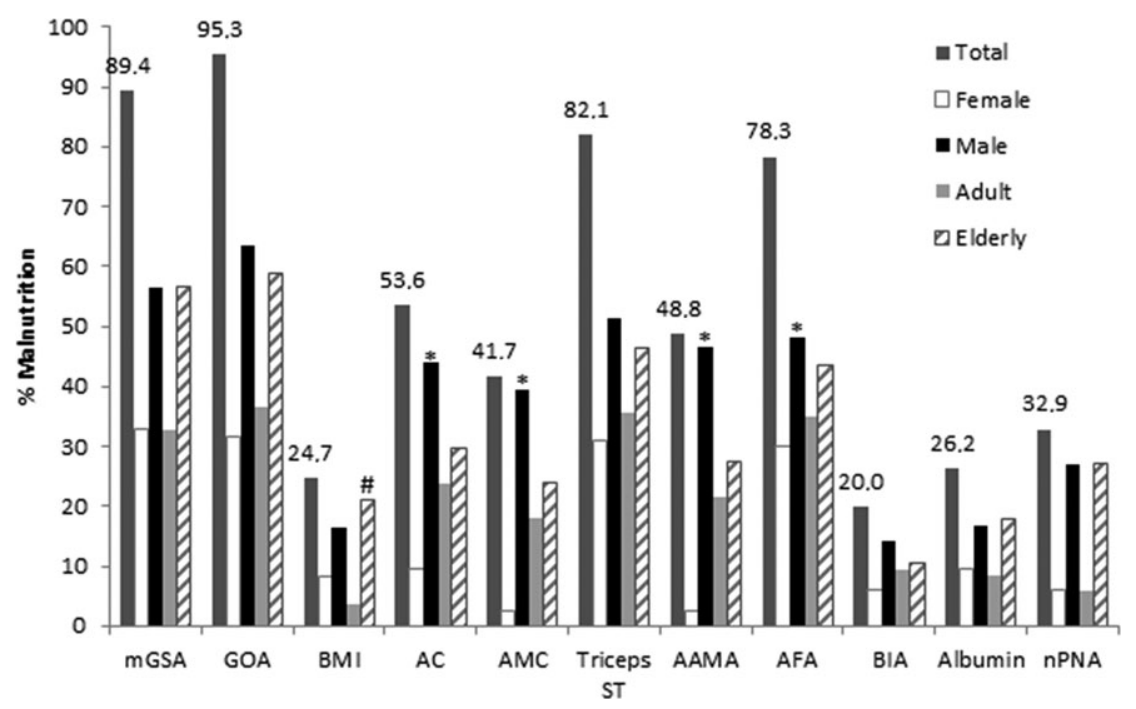

Figure 1 Malnutrition prevalence in haemodialysis patients by sex and age, according to different indicators $(n=85)$. mGSA, modified global subjective assessment; GOA, global objective assessment; BMI, body mass index; AC, arm circumference; AMC, arm muscle circumference; ST, skinfold thickness; AAMA, adjusted-arm muscle area; AFA, fat arm area; BIA, electrical bioimpedence; nPNA, normalised protein equivalent of nitrogen appearance. ${ }^{* \#} P<0.05$ by Pearson's chi-squared test or Fisher's exact test for comparision between sex and age.

presented as being at high risk and $23.5 \%$ as being at very high risk of metabolic complications associated with central obesity by WHO criteria ${ }^{(28)}$, with the occurrence of very high risk being more relevant among women $(20.0 \%$, WC $\geq 88 \mathrm{~cm})$. By the IDF ${ }^{(29)}, 61.2 \%$ of the individuals presented abdominal obesity. According to the WHR, 52.9\% had a risk of cardiovascular disease, with a higher frequency for females (Table 1).

The BF\% obtained by the $\Sigma 4 \mathrm{p}$ method identified, respectively, a lack of and excess fat in $22.7 \%$ and $48.8 \%$ of individuals. The prevalence of the body fat excess category was statistically higher among males. With regard to age, the frequencies of body fat scarcity and obese categories were higher in adults and elderly, respectively (Table 1).

According to BIA, $20.0 \%$ of individuals showed a lack of fat and $23.5 \%$ showed fat excess. By the physical constitution scale, $15.3 \%$ of the individuals were classified as being underweight and $28.2 \%$ as overweight; $20 \%$ had excessive levels of visceral fat, and the prevalence of this category was statistically higher among elderly individuals (Table 1).

Table 2 shows anthropometric and body composition variables of HD patients, according to malnutrition diagnosis by the GOA. In this sense, the BMI was reduced across adequate, risk of malnutrition and malnutrition diagnosis levels. Values of WC, fat mass and visceral fat levels from BIA were significantly lower in malnourished subjects compared to those who had adequate levels or were at risk of malnutrition. The physical constitution scale and nPNA were significantly lower in malnourished subjects compared to those with adequate values. We also performed a comparison between anthropometric and body composition variables across malnutrition diagnosis using the mGSA (Adequate and Nutritional risk/mild malnutrition) and there were no statistically significant differences between groups for any variable (data not shown).

Finally, ROC curve analysis was used to confirm the sensitivity of mGSA and GOA in relation to successful $\mathrm{HD}$, as evaluated by Kt/V urea. The ROC curve is a line graph that plots the probability of a true positive result (test sensitivity) versus the probability of a false positive result for a number of different cutoff.

Thus, the AUC was 0.658 [95\% confidence interval $(\mathrm{CI})=0.519-0.797]$ for arm muscle circumference, 0.644 (95\% CI $=0.506-0.781)$ for adjusted arm muscle area, $0.536(95 \% \mathrm{CI}=0.390-0.682)$ for $\mathrm{BMI}, \quad 0.530 \quad(95 \%$ $\mathrm{CI}=0.381-0.678) \quad$ for $\quad \mathrm{BF} \% \quad$ by $\mathrm{BIA}, \quad 0.526 \quad(95 \%$ $\mathrm{CI}=0.316-0.616)$ for GOA and $0.524(95 \% \mathrm{CI}=0.288-$ 0.591) for mGSA (Fig. 2).

\section{Discussion}

The present study aimed to evaluate the clinical and nutritional status and body composition of individuals undergoing $\mathrm{HD}$, with an emphasis on a comparison between the diagnoses provided by biochemical and classic anthropometric indicators and those obtained by GOA and mGSA. A higher frequency of malnourished individuals was observed when using the GOA (95.3\%) and this was lower using the BIA (20.0\%). After the GOA and mGSA, the arm fat area and triceps ST indicators 
Table 1 Overweight and cardiometabolic risk prevalence in haemodialysis patients by gender and age, according to anthropometric indicators and bioelectrical impedance $(n=85)$

\begin{tabular}{|c|c|c|c|c|c|c|c|}
\hline & $\begin{array}{l}\text { Total } \\
(n=85) \\
n(\%)\end{array}$ & $\begin{array}{l}\text { Female } \\
(n=29) \\
n(\%) *\end{array}$ & $\begin{array}{l}\text { Male } \\
(n=56) \\
n(\%)^{*}\end{array}$ & $P$ & $\begin{array}{l}\text { Adult } \\
(n=33) \\
n(\%) *\end{array}$ & $\begin{array}{l}\text { Elderly } \\
(n=52) \\
n(\%) *\end{array}$ & $P$ \\
\hline \multicolumn{8}{|l|}{ BMI } \\
\hline Underweight & $21(24.7)$ & $7(8.2)$ & $14(16.5)$ & & $3(3.5)^{a}$ & $18(21.2)^{b}$ & \\
\hline Normal weight & $47(55.3)$ & $14(16.5)$ & $33(38.8)$ & 0.435 & $24(28.2)^{a}$ & $23(27.1)^{a}$ & 0.015 \\
\hline Overweight & $17(20.0)$ & $8(9.4)$ & $9(10.6)$ & & $6(7.1)^{a}$ & $11(12.9)^{a}$ & \\
\hline \multicolumn{8}{|l|}{ WC (WHO, 1998) } \\
\hline No risk & $46(54.1)$ & $3(3.5)^{a}$ & $43(50.6)^{b}$ & & $19(22.4)$ & $27(31.8)$ & \\
\hline High risk & $19(22.4)$ & $9(10.6)^{a}$ & $10(11.8)^{\mathrm{a}}$ & $<0.001$ & $7(8.2)$ & $12(14.1)$ & 0.872 \\
\hline Very high risk & $20(23.5)$ & $17(20.0)^{a}$ & $3(3.5)^{b}$ & & $7(8.2)$ & $13(15.3)$ & \\
\hline \multicolumn{8}{|l|}{ WC (IDF, 2005) ${ }^{(27)}$} \\
\hline Adequate & $33(38.8)$ & $3(3.5)$ & $30(35.3)$ & $<0.001$ & $16(18.8)$ & $17(20.0)$ & 0.145 \\
\hline Inadequate & $52(61.2)$ & $26(30.6)$ & $26(30.6)$ & & $17(20.0)$ & $35(41.2)$ & \\
\hline \multicolumn{8}{|l|}{ WHR } \\
\hline No risk & $40(47.1)$ & $2(2.4)$ & $38(44.7)$ & $<0.001$ & $19(22.4)$ & $21(24.7)$ & 0.122 \\
\hline Risk & $45(52.9)$ & $27(31.8)$ & $18(21.2)$ & & $14(16.5)$ & $31(36.5)$ & \\
\hline \multicolumn{8}{|l|}{ BF\% $\Sigma 4 S T$} \\
\hline Not recommended & $5(6.0)$ & $0^{a}$ & $5(6.0)^{a}$ & & $1(1.2)^{\mathrm{a}}$ & $4(4.8)^{a}$ & \\
\hline Scarcity & $14(16.7)$ & $4(4.8)^{a}$ & $10(11.9)^{\mathrm{a}}$ & & $10(11.9)^{a}$ & $4(4.8)^{b}$ & \\
\hline Normal & $24(28.6)^{a}$ & $12(14.3)^{\mathrm{a}}$ & $12(14.3)^{a}$ & 0.011 & $11(13.1)^{\mathrm{a}}$ & $13(15.5)^{a}$ & 0.029 \\
\hline Excess & $17(20.2)$ & $1(1.2)^{\mathrm{a}}$ & $16(19.0)^{b}$ & & $6(7.1)^{a}$ & $11(13.1)^{a}$ & \\
\hline Obesity & $24(28.6)$ & $11(13.1)^{\mathrm{a}}$ & $13(15.5)^{\mathrm{a}}$ & & $5(6.0)^{a}$ & $19(22.6)^{b}$ & \\
\hline \multicolumn{8}{|l|}{$\mathrm{BF} \% \mathrm{BIA}$} \\
\hline Fat lack & $17(20.0)$ & $5(5.9)$ & $12(14.1)$ & & $8(9.4)$ & $9(10.6)$ & \\
\hline Healthy & $48(56.5)$ & $19(22.4)$ & $29(34.1)$ & & $17(20.0)$ & $31(36.5)$ & \\
\hline Fat excess & $16(18.8)$ & $3(3.5)$ & $13(15.3)$ & 0.402 & $7(8.2)$ & $9(10.6)$ & 0.752 \\
\hline Obese & $4(4.7)$ & $2(2.4)$ & $2(2.4)$ & & $1(1.2)$ & $3(3.5)$ & \\
\hline \multicolumn{8}{|c|}{ Physical constitution scale BIA } \\
\hline Weight low & $13(15.3)$ & $3(3.5)$ & $10(11.8)$ & & $7(8.2)$ & $6(7.1)$ & \\
\hline Healthy weight & $47(55.3)$ & $19(22.4)$ & $28(32.9)$ & 0.509 & $15(17.6)$ & $32(37.6)$ & 0.280 \\
\hline Overweight & $24(28.2)$ & $7(8.2)$ & $17(20.0)$ & & $10(11.8)$ & $14(16.5)$ & \\
\hline \multicolumn{8}{|l|}{ Visceral fat level BIA } \\
\hline Healthy level & $68(80.0)$ & $26(30.6)$ & $42(49.4)$ & 0.109 & 32 (37.6) & $36(42.4)$ & 0.002 \\
\hline Excessive level & $17(20.0)$ & $3(3.5)$ & 14 (16.5) & & $1(1.2)$ & 16 (18.8) & \\
\hline
\end{tabular}

BMI, body mass index; BF, body fat; BIA: electrical bioimpedance; WC, waist circumference; WHR, waist-hip ratio; $\Sigma 4 p$, sum of four skinfolds thickness.

*In the total sample. $P$ represents Pearson's chi-squared test or Fisher's exact test.

Values followed by different superscript letters within a column are significantly different $(P<0.05)$. Where there was no statistically significant difference, the letter was omitted.

The values of $p$ in bold mean that they were less than 0.05 in the statistical tests.

detected, similarly, a higher prevalence of malnutrition, showing that these anthropometric indicators of fat reserves were also more sensitive.

This result is similar to those described previously in previous studies ${ }^{(41,42)}$. However, several factors influence the variation in the prevalence of malnutrition in the different studies. Among the differences between the countries where the studies are carried out, it is possible to note sample heterogeneity and a diversity in eating patterns, socio-economic status and comorbidities ${ }^{(43)}$, and also the various factors that contribute to the development of malnutrition ${ }^{(41)}$, as well as the dose and HD conditions ${ }^{(44)}$.
The mGSA is a full quantitative method, adapted and validated for the diagnosis of PEM in individuals on dialysis and is related to morbidity and mortality in this population ${ }^{(13,45,46)}$. The GOA, has the same function as the mGSA; however, it is rarely used to assess the nutritional status of individuals undergoing HD. Thus, it should be applied in association with mGSA, and it is important to check the relationship of the diagnosis provided by both methods with other objective indicators.

The categorical classification of GOA showed a relationship with the evaluated indicators to the extent that the ratings of nutritional risk/mild malnutrition and mainly moderate malnutrition were accompanied by a 
Table 2 Anthropometric and body composition variables of haemodialysis patients, according to malnutrition diagnosis by the Global Objective Assessment $(n=85)$

\begin{tabular}{|c|c|c|c|c|}
\hline Variables & $\begin{array}{l}\text { Adequate } \\
\text { nutrition }(n=4)\end{array}$ & $\begin{array}{l}\text { Nutritional risk/mild } \\
\text { malnutrition }(n=75)\end{array}$ & $\begin{array}{l}\text { Moderate } \\
\text { malnutrition }(n=6)\end{array}$ & $P$ \\
\hline $\mathrm{BMI}\left(\mathrm{kg} \mathrm{m}^{-2}\right)$ & $28.9(4.1)^{a}$ & $23.6(3.3)^{b}$ & $18.4(1.0)^{c}$ & $<0.001$ \\
\hline $\mathrm{AC}(\mathrm{cm})$ & $32.2\left(5.2^{\mathrm{a}}\right.$ & $27.5(3.6)^{b}$ & $26.83(4.1)^{a . b}$ & 0.043 \\
\hline Arm muscle circumference $(\mathrm{cm})$ & $27.7(3.3)$ & $24.3(2.9)$ & $24.2(4.9)$ & 0.111 \\
\hline Adjusted-arm muscle area $\left(\mathrm{cm}^{2}\right)$ & $54.5(37.2-68.5)$ & $39.4(32.1-44.0)$ & $34.5(26.0-47.7)$ & 0.134 \\
\hline Arm fat area $\left(\mathrm{cm}^{2}\right)$ & $18.4(8.8-28.7)$ & $10.8(7.2-15.2)$ & $6.1(4.6-15.1)$ & 0.097 \\
\hline Triceps ST (mm) & $15.1(7.2-20.9)$ & $9.6(6.8-14.0)$ & $5.0(3.8-15.5)$ & 0.165 \\
\hline WC $(\mathrm{cm})$ & $98.8(8.8)^{\mathrm{a}}$ & $90.2(9.4)^{a}$ & $76.3(5.6)^{b}$ & $<0.001$ \\
\hline WHR & $0.97(0.95-1.00)^{a . b}$ & $0.98(0.92-1.02)^{a}$ & $0.89(0.84-0.93)^{b}$ & 0.033 \\
\hline Fat mass $\Sigma 4 S T(\mathrm{~kg})$ & $23.1(7.1)^{\mathrm{a}}$ & $14.3(5.6)^{\mathrm{b}}$ & $8.8(6.1)^{b}$ & 0.001 \\
\hline Lean mass $\Sigma 4 S T$ (kg) & $46.3(5.3)$ & $46.6(9.5)$ & $43.0(7.5)$ & 0.604 \\
\hline Fat mass BIA $(\mathrm{kg})$ & $23.7(1.3-31.3)^{a}$ & $13.4(9.4-17.6)^{a}$ & $6.2(3.4-8.5)^{b}$ & 0.002 \\
\hline Lean mass BIA $(\mathrm{kg})$ & $43.4(5.4)$ & $44.8(9.1)$ & $42.9(5.6)$ & 0.845 \\
\hline Visceral fat level BIA & $12.8(2.2)^{\mathrm{a}}$ & $9.3(4.0)^{a}$ & $6.5(1.4)^{b}$ & 0.047 \\
\hline Physical constitution scale BIA & $2.0(2.0-2.8)^{a}$ & $5.0(2.8-5.0)^{a . b}$ & $7.0(4.0-7.0)^{b}$ & 0.017 \\
\hline Albumin $\left(\mathrm{g} \mathrm{dL}^{-1}\right)$ & $4.5(4.2-4.7)$ & $4.1(3.9-4.3)$ & $4.1(4.0-4.3)$ & 0.074 \\
\hline nPNA $\left(\mathrm{g} \mathrm{kg}^{-1} \mathrm{dia}^{-1}\right)$ & $1.3(0.1)^{a}$ & $1.1(0.2)^{a . b}$ & $0.9(0.2)^{b}$ & 0.031 \\
\hline
\end{tabular}

AC, arm circumference; BMI, body mass index; BIA, electrical bioimpedance; BF, body fat; nPNA, normalised protein equivalent of nitrogen appearance; ST, skinfold thickness; WC, waist circumference; WHR, waist-hip ratio; $24 S T$, sum of four skinfolds thickness.

Values expressed as the mean (SD) or median and interquartile range, according to the data distribution.

$P$ represents analysis of variance, complemented by Hochberg's GT2 test, or a Games-Howell or Kruska-Wallis, complemented by Bonferroni correction.

Values followed by different superscript letters are significantly different $(P<0.05)$. Where there was no difference, the letter was omitted. The values of $p$ in bold mean that they were less than 0.05 in the statistical tests.

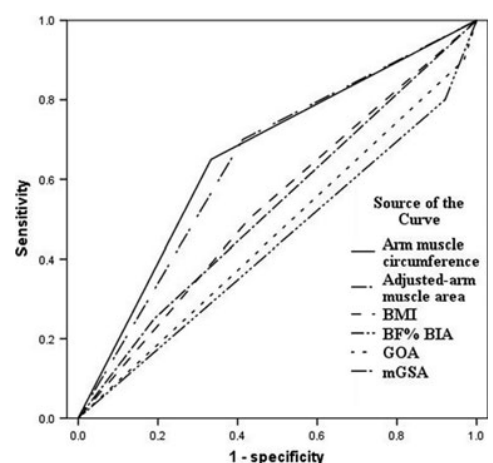

Figure 2 Receiver operator characteristic curve for different variables of malnutrition in relation to successful haemodialysis (by KtN urea). $\mathrm{BMI}$, body mass index; \%BF BIA, percentage of body fat by electrical bioimpedance; GOA, global objective assessment; mGSA, modified global subjective assessment.

significant decrease in the values of anthropometric and body composition variables. Morais et al. ${ }^{(20)}$ also found a positive correlation of GOA only for BMI in 44 adults and elderly undergoing $\mathrm{HD}$, although GOA was not related to three biochemical markers (serum albumin, transferrin and lymphocyte total count).

We did not identify this relationship across mGSA classification. The same outcome was observed in other studies ${ }^{(10,47)}$. This result can be explained by the fact that $\mathrm{mSGA}$ is qualitative and a more sensitive method for the diagnosis of malnutrition. By taking into consideration objective variables, the GOA becomes a more specific method, and presents a better correlation with the studied variables.

In the ROC curve analyses, mGSA and GOA were good indicators for diagnosing malnutrition because both achieved an AUC $>0.5$ in relation to successful HD by $\mathrm{Kt} / \mathrm{V}$ urea. Given these results, these nutritional risk scores are useful indicators for the nutritional diagnosis in HD individuals.

Three methods ( $\Sigma 4$ ST, BIA and the physical constitution scale) were used to evaluate health risk by body fat excess and indicated categories of adiposity below the desired level, which is an advantage when assessing individuals undergoing $\mathrm{HD}$ because the body fat reserves appear to offer protection against treatment exploitative conditions (48) and the lack of fat tissue, which is indicative of malnutrition, is a factor that contributes for mortality ${ }^{(49) .}$

Despite the possible protection offered by weight excess, studies have shown that HD obese patients had lower scores of quality of life compared to other individuals ${ }^{(50)}$. Furthermore, central fat has been associated with cardiometabolic disorders ${ }^{(51)}$, cardiovascular events (52) and mortality in these individuals.

Thus, in addition to using different indicators for the early diagnosis of nutritional risk, the assessment of 
cardiometabolic risk also becomes important. In this sample, despite the high risk of malnutrition, the presence of cardiometabolic risk was indicated using different methods.

According to the WHR, $52.9 \%$ had a risk of cardiovascular disease and, by WC, $61.2 \%$ were at risk of diseases associated with obesity. Moreover, among these patients with a high WHR, none had excessive body fluids and, for this reason, water retention did not influence the measurement and, because there was no interference, WHR may be used without the risk of misinterpretation (data not shown).

Recent studies have stressed that the type and fat distribution, rather than total fat, is a determinant of longterm risk factor complications ${ }^{(53)}$ and increased muscle mass reserves and body fat are shown to be protective ${ }^{(54)}$. These studies suggest that an assessment of the body composition and especially the regionalisation of the body fat of these individuals is important because, in the present study, $20.0 \%$ had a high VAT and, from all patients with adequate BMI levels, 17\% showed a high VAT.

In this context, BIA is a non-invasive method with high reproducibility and specificity ${ }^{(55,56)}$ and assesses the dry weight ${ }^{(57,58)}$, body composition, nutritional status $(59,60)$ and hydration of HD individuals ${ }^{(61,62)}$.

The recommendation is that BIA is used as a complementary diagnostic tool for assessing the nutritional status of individuals undergoing $\mathrm{HD}$, as associated with subjective methods, as well as anthropometric and classical biochemical indicators ${ }^{(63)}$. In addition, BIA can be an important tool for decision-making related to weight changes in individuals undergoing $\mathrm{HD}{ }^{(64)}$, allowing the nutritional advice to be improved upon and adjusted from the results obtained ${ }^{(65)}$.

Considering the results obtained in the present study, as well as the information extracted by the mGSA and GOA, and the possibility that they report the nutritional diagnosis, their indication as preferred methods for identifying malnutrition in HD patients is confirmed. On the other hand, when the evaluation focuses on identifying overweight individuals and characterising body composition, BIA assumes a significant role in the nutritional diagnosis.

\section{Conclusions}

The mGSA and GOA were the most sensitive indicators for identifying individuals at malnutrition risk compared to the isolated anthropometric indicators. Thus, mGSA and GOA are applicable indicators for evaluation of elderly and adults in HD, and should preferably be used together to detect malnutrition because they are complementary and showed good agreement with each other. Moreover, the same individuals at high nutritional risk presented the occurrence of cardiometabolic risk, as diagnosed by different methods, with an emphasis on those that assessed central fat distribution. In addition, BIA comprised a useful tool complementing the nutritional diagnosis of these individuals, making it possible to evaluate the regionalisation of fat and hydration status.

\section{Transparency declaration}

The lead author affirms that this manuscript is an honest, accurate and transparent account of the study being reported, that no important aspects of the study have been omitted and that any discrepancies from the study as planned have been explained. The reporting of this work is compliant with STROBE guidelines.

\section{Acknowledgments}

We thank the volunteers and acknowledge the master's and doctoral scholarships from CAPES and CNPq. We also thank the FAPEMIG (Minas Gerais/Brazil) and CNPq for financial support. H. H. M. Hermsdorff is CNPq fellow.

\section{Conflict of interests, source of funding and authorship}

The authors declare that they have no conflicts of interest.

Funding was provided by the FAPEMIG (Minas Gerais/Brazil) and CNPq.

KPB was responsible for the study design, field work, data collection, analysis and the writing of the manuscript. APSE and LDM were responsible for the study design, field work and data collection. SMRR was responsible for the study design and data interpretation. MGG was the project leader in São João Batista Hospital, and was responsible for study design and data interpretation. HHMH was project leader in the Universidade Federal de Viçosa, and was responsible for general coordination, study design and data interpretation. All authors critically reviewed the manuscript and approved the final version submitted for publication.

\section{References}

1. Dukkipati R \& Kopple JD (2009) Causes and prevention of protein-energy wasting in chronic kidney failure. Semin Nephrol 29, 39-49.

2. Tabibi H, As'habi A, Heshmati BN et al. (2012) Prevalence of protein-energy wasting and its various types in iranian 
hemodialysis patients: a new classification. Ren Fail 34, 1200-1205.

3. Muscaritoli M, Molfino A, Bollea MR et al. (2009) Malnutrition and wasting in renal disease. Curr Opin Clin Nutr Metab Care 12, 378-383.

4. Carrero JJ, Stenvinkel P, Cuppari L et al. (2013) Etiology of the protein-energy wasting syndrome in chronic kidney disease: a consensus statement from the International Society of Renal Nutrition and Metabolism (ISRNM). J Ren Nutr 23, 77-90.

5. De Mutsert R, Grootendorst DC, Axelsson J et al. (2008) Excess mortality due to interaction between protein-energy wasting, inflammation and cardiovascular disease in chronic dialysis patients. Nephrol Dial Transplant 23, 2957-2964.

6. Rambod M, Bross R, Zitterkoph J et al. (2009) Association of Malnutrition-Inflammation Score with quality of life and mortality in hemodialysis patients: a 5-year prospective cohort study. Am J Kidney Dis 53, 298-309.

7. Mazairac AH, De Wit GA, Penne EL et al. (2011) Proteinenergy nutritional status and kidney disease-specific quality of life in hemodialysis patients. J Ren Nutr 2, 376-386.

8. Steiber AL, Kalantar-Zadeh K, Secker D et al. (2004) Subjective Global Assessment in chronic kidney disease: a review. J Ren Nutr 14, 191-200.

9. Kalantar-Zadeh K, Ikizler TA, Block G et al. (2003) Malnutrition-inflammation complex syndrome in dialysis patients: causes and consequences. Am J Kidney Dis 42, 864-881.

10. Hou Y, Li X, Hong D et al. (2012) Comparison of different assessments for evaluating malnutrition in Chinese patients with end-stage renal disease with maintenance hemodialysis. Nutr Res 32, 266-271.

11. Chen J, Peng H, Yuan Z et al. (2013) Combination with anthropometric measurements and MQSGA to assess nutritional status in Chinese hemodialysis population. Int J Med Sci 10, 974-980.

12. Ruperto M, Sánchez-Muniz FJ \& Barril G (2016) Predictors of protein-energy wasting in haemodialysis patients: a crosssectional study. J Hum Nutr Diet 29, 38-47.

13. Kalantar-Zadeh K, Kleiner M, Dunne E et al. (1999) A modified quantitative subjective global assessment of nutrition for dialysis patients. Nephrol Dial Transplant 14, 1732-1738.

14. Enia G, Sicuso C, Alati G et al. (1993) Subjective global assessment of nutrition in dialysis patients. Nephrol Dial Transplant 8, 1094-1098.

15. Detsky AS, Mclaughlin JR, Baker JP et al. (1987) What is subjective global assessment of nutritional status? J Parenter Enteral Nutr 11, 8-13.

16. Canada-USA (CANUSA) Peritoneal Dialysis Study Group (1996) Adequacy of dialysis and nutrition in continuous peritoneal dialysis: association with clinical outcomes. J Am Soc Nephrol 7, 198-207.

17. Jones CH, Wolfenden RC \& Wells LM (2004) Is subjective global assessment a reliable measure of nutritional status in hemodialysis? J Ren Nutr 14, 26-30.
18. As'habi A, Tabibi H,Nozary-Heshmati B et al. (2014) Comparison of various scoring methods for the diagnosis of protein-energy wasting in hemodialysis patients. Int Urol Nephrol 46, 999-1004.

19. Martins C (2001) Protocolo de Procedimentos Nutricionais. In: Nutrição e o Rim. pp. 311-354 [Riella MC \& Martins C, editors]. Rio de Janeiro: Guanabara Koogan.

20. Morais AAC, Silva MAT, Faintuch J et al. (2005) Correlation of nutritional status and food intake in hemodialysis patients. Clinics 60, 185-192.

21. Jeliffe DB (1968) Evaluation del estado de nutrición de la comunidad com especial referencia a lãs encuestas em lãs regions in desarrollo. Genebra: Organización Mundial de la Salud.

22. World Health Organization - WHO (1995) Physical status: The Use and Interpretation of Anthropometry. Geneva: Technical Report Series 854.

23. Coelho MASC \& Amorim RB (2007) Avaliação nutricional em geriatria. In: Avaliação nutricional: Aspectos clínicos e laboratoriais. pp. 155-176. [Duarte ACG, editor]. São Paulo: Atheneu.

24. Lohman TG, Roche AF \& Martorelli R (1991) Anthropometric Standardization Reference Manual. Abridged edn. Champaign, IL: Human Kinetics.

25. Frisancho AR (1981) New norms of upper limb fat and muscle áreas for assessment of the nutritional status. Am J Clin Nutr 34, 2540-2545.

26. Gurney JM \& Jeliffe DB (1973) Arm anthropometry in nutritional assessment: nomogram for rapid calculation of muscle circumference and cross-sectional muscle and fat areas. Am J Clin Nutr 26, 912-915.

27. Heymsfield SB, McManus C, Smith J et al. (1982) Anthropometric measurement of muscle mass: revised equations for calculating bone-free arm muscle area. Am J Clin Nutr 36, 680-690.

28. World Health Organization - WHO. (1998) Obesity: Preventing and Managing the Global Epidemic. pp. 276. Geneva: Report of a WHO Consulation on Obesity.

29. Grundy SM, Cleeman JJ, Daniels SR et al. (2005) Diagnosis and management of the metabolic syndrome: an American Heart Association/National Heart, Lung, and Blood Institute Scientific Statement. Circulation 112, 2735-2752.

30. Durnin JVGA \& Womersley I (1974) Body fat assessed from total body density ad its estimation from skinfold thickness: measurement on 481 men and women aged from 16 to 72 years. Br J Nutr 32, 77-97.

31. Siri WE (1961) Body composition from fluids spaces and density: analyses of methods. In: Techniques for Measuring Body Composition. pp. 223-244.Washington, DC: National Academy of Science and Natural Resource Council.

32. World Health Organization (2000) Obesity: preventing and managing the global epidemic (No. 894). World Health Organization.

33. Lipschitz DA (1994) Screening for nutritional status in the elderly. Prim Care 21, 55-67. 
34. Frisancho AR (1990) Anthropometric Standards for the Assessment of Growth and Nutritional Status. Ann Arbor, MI: The University of Michigan Press.

35. Blackburn GL \& Thornton PA (1979) Nutritional assessment of the hospitalized patients. Med Clin North Am 63, 1103-1115.

36. Rombeau JL editor. (1989) Atlas of Nutritional Support Techniques. Boston, MA: Little, Brown.

37. NIH/WHO BMI Guidelines (2001). https://www.nih.gov/ (accessed August 2016)

38. Gallagher D, Heymsfield SB, Heo M et al. (2000) Healthy percentage body fat ranges: an approach for developing guidelines based on body mass index. Am J Clin Nutr 72, 694-701.

39. National Kidney Foundation (2000) (K/DOQI). Clinical Practice Guidelines for Nutrition in Chronic Renal Failure. Am J Kidney Dis 35, S1-S3.

40. Yang SC, Chiang CK, Hsu SP et al. (2008) Relationship between interdialytic weight gain and nutritional markers in younger and older hemodialysis patients. J Ren Nutr 18, 210-222.

41. Oliveira CMC, Kubrusly M, Mota RS et al. (2010) Desnutrição na insuficiência renal crônica: qual o melhor método diagnóstico na prática clínica? J Bras Nefrol 32, 57-70.

42. Kaya T, Sipahi S, Karacaer C et al. (2014) Evaluation of nutritional status with different methods in geriatric hemodialysis patients: impact of gender. Int Urol Nephrol 46, 2385-2391.

43. Mohammed FA, Farhood HF \& Abdul-Atheemwtwt M (2014) Prediction of Malnutrition Using Modified Subjective Global Assessment-Dialysis Malnutrition Score in Patients on Chronic Hemodialysis. J Community Med Health Educ 4, 291.

44. Schulman G (2004) The dose of dialysis in hemodialysis patients: impact on nutrition. Semin Dial 17,479-488.

45. Riella MC (2013) Nutritional evaluation of patients receiving dialysis for the management of protein-energy wasting: what is old and what is new? J Ren Nutr 23, 195-198.

46. Yamada K, Furuya R, Takita T et al. (2008) Simplified nutritional screening tools for patients on maintenance hemodialysis. Am J Clin Nutr 87, 106-113.

47. Sedhain A, Hada R, Agrawal RK et al. (2015) Assessment of Nutritional Status of Nepalese Hemodialysis Patients by Anthropometric Examinations and Modified Quantitative Subjective Global Assessment. Nutr Metab Insights 8, 21-27.

48. Kakiya R, Shoji T, Tsujimoto Y et al. (2006) Body fat mass and lean mass as predictors of survival in hemodialysis patients. Kidney Int 70, 549-556.

49. Rosenberger J, Kissova V, Majernikova M et al. (2014) Body composition monitor assessing malnutrition in the hemodialysis population independently predicts mortality. J Ren Nutr 24, 172-176.

50. Johansen KL, Kutner NG, Young B et al. (2006) Association of body size with health status in patients beginning dialysis. Am J Clin Nutr 83, 543-549.
51. Postorino M, Marino C, Tripepi G et al. (2009) Abdominal obesity and all-cause and cardiovascular mortality in endstage renal disease. J Am Coll Cardiol 53, 1265-1272.

52. Elsayed EF, Tighiouart H, Weiner D et al. (2008) Waistto-hip ratio and body mass index as risk factors for cardiovascular events in CKD. Am J Kidney Dis 52, 49-57.

53. Cordeiro AC, Qureshi AR, Stenvinkel P et al. (2010) Abdominal fat deposition is associated with increased inflammation, protein-energy wasting and worse outcome in patients undergoing hemodialysis. Nephrol Dial Transplant 25, 562-568.

54. Park J, Ahmadia SF, Strejaa E et al. (2014) Obesity paradox in end-stage kidney disease patients. Prog Cardiovasc Dis 56, 415-425.

55. Wabel P, Chamney P, Moissl U et al. (2009) Importance of whole-body bioimpedance spectroscopy for the management of fluid balance. Blood Purif 27, 75-80.

56. Moon JR, Stout JR, Smith AE et al. (2010) Reproducibility and validity of bioimpedance spectroscopy for tracking changes in total body water: implications for repeated measurements. Br J Nutr 104, 1384-1394.

57. Machek P, Jirka T, Moissl U et al. (2010) Guided optimization of fluid status in haemodialysis patients. Nephrol Dial Transplant 25, 538-544.

58. Passauer J, Petrov H, Schleser A et al. (2010) Evaluation of clinical dry weight assessment in haemodialysis patients using bioimpedance spectroscopy: a cross-sectional study. Nephrol Dial Transplant 25, 545-551.

59. Jacobs LH, Van De Kerkhof JJ, Mingels AM et al. (2010) Inflammation, overhydration and cardiac biomarkers in haemodialysis patients: a longitudinal study. Nephrol Dial Transplant 25, 243-248.

60. Donadio C, Consani C, Ardini M et al. (2005) Estimate of body water compartments and of body composition in maintenance hemodialysis patients: comparison of single and multifrequency bioimpedance analysis. J Ren Nutr 15, 332-344.

61. Van De Kerkhof J, Hermans M, Beerenhout C et al. (2004) Reference values for multifrequency bioimpedance analysis in dialysis patients. Blood Purif 22, 301-306.

62. Park J, Chung HC, Kim MS et al. (2009) Relationship between extracellular water fraction of total body water estimated by bioimpedance spectroscopy and cardiac troponin $\mathrm{T}$ in chronic haemodialysis patients. Blood Purif 28, 61-68.

63. Erdogan E, Tutal E, Uyar ME et al. (2013) Reliability of Bioelectrical Impedance Analysis in the Evaluation of the Nutritional Status of Hemodialysis Patients d A Comparison With Mini Nutritional Assessment. Transplant Proc 45, 3485-3488.

64. Gallar-Ruiz P, Di-Giois C, Lacalle C et al. (2012) Body composition in patients on haemodialysis: relationship between the type of haemodialysis and inflammatory and nutritional parameters. Nefrologia 32, 467-476.

65. Garagarza C, João-Matias P, Sousa-Guerreiro C et al. (2013) Nutritional status and overhydration: can bioimpedance spectroscopy be useful in haemodialysis patients? Nefrologia 33, 667-674. 